\title{
A Noninvasive Approach to Body Composition in the Neonate: Dynamic Skinfold Measurements
}

\author{
Yves W. Brans, ${ }^{[54]}$ James E. Sumners, Harry S. Dwegk, and George Cassady \\ Division of Perinatal Medicine, Perinatal Research Laboratory, Department of Pediatrics, University of Alabama Medical Center, \\ Birmingham, Alabama, USA
}

\section{Extract}

Midtricipital (MT) and subscapular (SS) skinfolds were measured within $24 \mathrm{hr}$ of birth in 23 normally grown mature (NG-M); 23 normally grown premature (NG-P); 6 intrauterine growth-retarded mature (IGR-M); and 7 intrauterine growth-retarded premature (IGR-P) infants. A rapid initial decrease in measured skinfold thickness (SFT) occurred after application of a Harpenden caliper, but readings stabilized by $60 \mathrm{~s}\left(\mathrm{SFT}_{60}\right)$. Measurements were recorded at 15 and $60 \mathrm{~s}$. The difference between 15- and 60-s readings was expressed in percentage of the 15-s reading (percentage $\triangle \mathrm{SFT}$ ).

The amount of subcutaneous fat, estimated from the $\mathrm{SFT}_{60}$ measurements, was affected by duration of gestation in the NG-M and NG-P and the IGR-M and IGR-P groups. In both NG groups, good linear correlations with birth weight $(r=0.852$ at $\mathrm{MT}$ and 0.874 at SS, $P<0.001)$ and with gestational age $(\mathrm{r}=0.842$ at $\mathrm{MT}$ and $\mathrm{r}=$ 0.804 at SS, $p<0.001)$ were evident. Values for intrauterine growth-retarded infants deviated markedly from the mean $\mathrm{SFT}_{60}$ expected for their gestational age.

Percentage $\triangle \mathrm{SFT}$ was affected by duration of maturation but not by impaired intrauterine growth. It correlated with gestational age $(\mathrm{r}=-0.777$ at $\mathrm{MT}$ and -0.773 at SS, $P<0.001)$ and with maximal postnatal weight loss $(\mathrm{r}=0.579$ at $\mathrm{MT}$ and 0.553 at SS, $P<0.001)$ in all groups and with birth weight in the premature groups only $(\mathrm{r}=-0.479$ at MT and -0.520 at SS, $P<0.01)$. The similarity of these trends with those of direct extracellular water measurements suggested that percentage $\Delta$ SFT may be an estimate of subcutaneous interstitial water.

\section{Speculation}

Changes in body composition during fetal life include fat deposition in the subcutaneous and internal body stores and a decrease in the proportion of body weight occupied by water. Intrauterine growth retardation results in lower fat stores and expansion of all body water compartments. The present data suggest that skinfold thickness recorded $60 \mathrm{~s}$ after caliper application and the difference between the 15and 60 -s readings provide estimates of fat stores and subcutaneous interstitial water, respectively. Caliper skinfold measurements can therefore be used for noninvasive studies of perinatal body composition and nutrition. 


\section{Introduction}

Recent investigations have shown that duration and quality of intrauterine development affect body composition of the neonate. Previous studies from this laboratory have dealt with changes in body water compartments [11-13], but lack of precise information on the amount of adipose tissue hampered further interpretation of the data in terms of lean body mass [13].

Present methods for assessing body fat contents in vivo lack precision. Direct measurements of total body fat by fat-soluble gas dilution techniques $[34,35]$ are not applicable to infants. Estimates based on various relations between height and weight are inadequate $[18,43]$. Determination of the specific gravity of the body [42] is not feasible in infants. Calculation of the fat content from measurements of body weight and extracellular water space implies a constant relation between extracellular space and lean body mass [37, 41], but present measurements in neonates do not support this assertion [13]. Assessment of subcutaneous thickness by x-ray [27], electrical conductivity [2-5], and ultrasound [5] do not differentiate between fat and interstitial fluid.

Skinfold measurements in selected groups of children and young adults correlate well with specific gravity $(\mathrm{r}=0.59-0.62[6,16,42,43,45])$, electrical conductivity $(r=0.81[5])$, ultrasound $(r=0.81[5])$, radiologic techniques $(\mathrm{r}=0.85$ to $0.88[27,45])$, and calculations based on measurements of the extracellular space $(\mathrm{r}=0.82[18])$. A good correlation between skinfold thickness and amount of carcass fat has been demonstrated in rats [39]. The method has been used extensively to evaluate degrees of obesity $[1,6,18,27,32$, $43]$ and to assess nutritional status in underdeveloped countries [24-26, 29, 38].

Reports on skinfold thickness in the newborn suggest a relation with maturity [28] and adequacy of intrauterine growth $[48,49]$. The purpose of this paper is to present observations concerning the measurement of skinfold thickness in 59 neonates within $24 \mathrm{hr}$ of birth and to discuss the dynamics of subcutaneous fat accretion and interstitial water accumulation during fetal life. Preliminary data have been reported previously [44].

\section{Materials and Methods}

Fifty-nine newborn infants born between March 1972 and April 1973 were studied within $24 \mathrm{hr}$ of birth. They were selected randomly from the nursery popula- tion according to availability of parental consent for inclusion in a study of feeding methods. They belonged to four groups according to their degree of intrauterine maturation and growth: NG-M, 23 infants; NG-P, 23 infants; IGR-M, 6 infants; and IGR-P, 7 infants. Gestational age was determined from the menstrual history of the mother in all but one NG-P and four IGR-P for whom Dubowitz's criteria [15] were used in lieu of vague maternal histories. In all other cases Dubowitz scores confirmed histories. A gestation of less than 37 weeks defined prematurity and a birth weight below the 10th percentile for gestational age, sex, and race [23] defined intrauterine growth retardation.

By means of a Harpenden caliper [18, 45], with the infant lying prone, one of three investigators measured the SFT at two sites: over the left triceps, midway between the posterior border of the tip of the acromion and the olecranon (MT) and below the lower angle of the left scapula (SS). As deep a vertical fold as could be obtained without unduly stretching the skin was lifted between the thumb and index finger of one hand, care being taken not to include muscle nor to squeeze the fold. Measurements were obtained to the nearest $0.05 \mathrm{~mm}$ exactly 15 and $60 \mathrm{~s}$ after application of the caliper. The 60 -s reading will be referred to as $\mathrm{SFT}_{60}\left(\mathrm{MT}_{60}\right.$ or $\left.\mathrm{SS}_{60}\right)$ and the difference between the 15 and 60 -s readings, expressed as percentage of the 15-s value

$$
\left(\frac{\left(\mathrm{SFT}_{15}-\mathrm{SFT}_{60}\right)}{\mathrm{SFT}_{15}} \times 100\right),
$$

will be referred to as percentage $\Delta \mathrm{MT}$ or percentage $\Delta \mathrm{SS}$.

Weights were recorded daily to the nearest $10 \mathrm{~g}$ and the total postnatal weight loss

$$
\begin{aligned}
& \text { (percentage } \Delta \mathrm{W} \\
& \qquad \frac{\text { birth } w \mathrm{t}-\text { lowest postnatal } w t}{\text { birth } w t} \\
& \quad \times 100) .
\end{aligned}
$$

Regression analysis was applied to the data.

\section{Results}

Race, sex, gestational age, birth weight, and postnatal weight loss for each group are presented in Table $\mathrm{I}$. Of the 59 infants, 17 were Caucasian and 42 were Negro, but the proportion of Caucasians was higher in the 
Table I. Clinical characteristics of the four study groups ${ }^{1}$

\begin{tabular}{|c|c|c|c|c|}
\hline & \multicolumn{2}{|c|}{ Normally grown } & \multicolumn{2}{|c|}{ Intrauterine growth retarded } \\
\hline & Mature & Premature & Mature & Premature \\
\hline Number of infants & 23 & 23 & 6 & 7 \\
\hline Ratio of Caucasian to Negro & $3 / 20$ & $10 / 13$ & $3 / 3$ & $1 / 6$ \\
\hline Ratio of male to female & $13 / 10$ & $12 / 11$ & $4 / 2$ & $4 / 3$ \\
\hline Gestational age, wk & $\begin{array}{c}40.1 \pm 2.14 \\
(37-46)\end{array}$ & $\begin{array}{c}28.5 \pm 2.46 \\
(24-35)\end{array}$ & $\begin{array}{c}39.5 \pm 0.55 \\
(39-40)\end{array}$ & $\begin{array}{c}33.4 \pm 2.37 \\
(32-36)\end{array}$ \\
\hline Birth weight, $g$ & $\begin{array}{c}3,132 \pm 416.0 \\
(2,440-3,920)\end{array}$ & $\begin{array}{c}1,217 \pm 377.4 \\
(680-2,480)\end{array}$ & $\begin{array}{c}2,091 \pm 357.9 \\
(1,560-2,610)\end{array}$ & $\begin{array}{c}1,284 \pm 310.3 \\
(800-1,740)\end{array}$ \\
\hline Postnatal weight loss, $\% \Delta \mathrm{W}$ & $\begin{array}{c}4.4 \pm 2.14 \\
(0-9)\end{array}$ & $\begin{array}{l}13.4 \pm 5.21 \\
(4.8-26.2)\end{array}$ & $\begin{array}{c}5.7 \pm 4.41 \\
(0-11.1)\end{array}$ & $\begin{array}{c}5.8 \pm 3.45 \\
(2.6-12)\end{array}$ \\
\hline
\end{tabular}

${ }_{1}$ The mean ( \pm SD and range) is indicated where appropriate. Statistical analysis is discussed in the text.
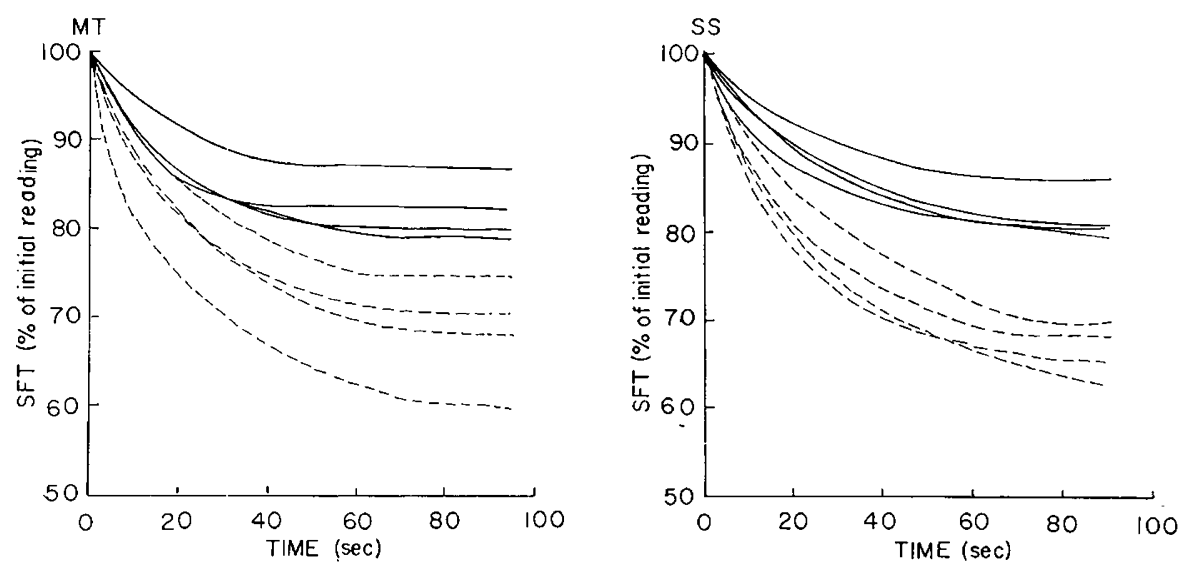

Fig. 1. Effect of duration of caliper application on skinfold thickness (SFT) measurements at midtricipital $(M T)$ and subscapular (SS) sites in four mature (-) and four premature neonates (--). Readings were obtained at the time of caliper application and every $10 \mathrm{~s}$ thereafter.

NG-P and IGR-M groups than in the others. Thirtythree infants were males and all groups showed a slight male predominance. Gestational ages ranged from 24 to 46 weeks. The mean gestational ages of the mature groups were similar although the NG-M group included two postmature births. The IGR-P group (with 1 of 7 babies under 30 weeks) was significantly more mature than the NG-P group (with 18 of 23 babies under 30 weeks $)(P<0.005)$. Birth weights ranged from 680 to $3920 \mathrm{~g}$ with 24 infants under 1,500 $\mathrm{g}, 12$ between 1,500 and $2,500 \mathrm{~g}$, and 23 above 2,500 g. The NG-P group had the highest mean postnatal weight loss, but both IGR groups were similar to the NG-M group in this respect.

In 4 NG-M and 4 NG-P babies, measurements were obtained at the time of caliper application and every $10 \mathrm{~s}$ thereafter. As shown in Figure 1, skinfold thickness readings at both sites declined exponentially during the 1st min of caliper application, with generally stable values from 60 to $90 \mathrm{~s}$. Fifteen seconds after caliper application was selected as the most conveninet time to take an accurate reading. Good correlations were obtained between $\mathrm{SFT}_{60}$ measurements at the $\mathrm{MT}$ and $\mathrm{SS}$ sites $(\mathrm{r}=0.911, P<0.001)$. In the NG groups, $\mathrm{SFT}_{60}$ correlated well with birth weight (Figure 2: $\mathrm{r}=0.862$ for MT and $\mathrm{r}=0.874$ for SS, $P<0.001$ ) and with gestational age (Figure 3: $\mathrm{r}=0.842$ for $\mathrm{MT}$ and 0.804 for SS, $P<0.001$ ). Both relations appeared to be linear, although the paucity of values for normally grown infants of birth weights between 1,500 and 


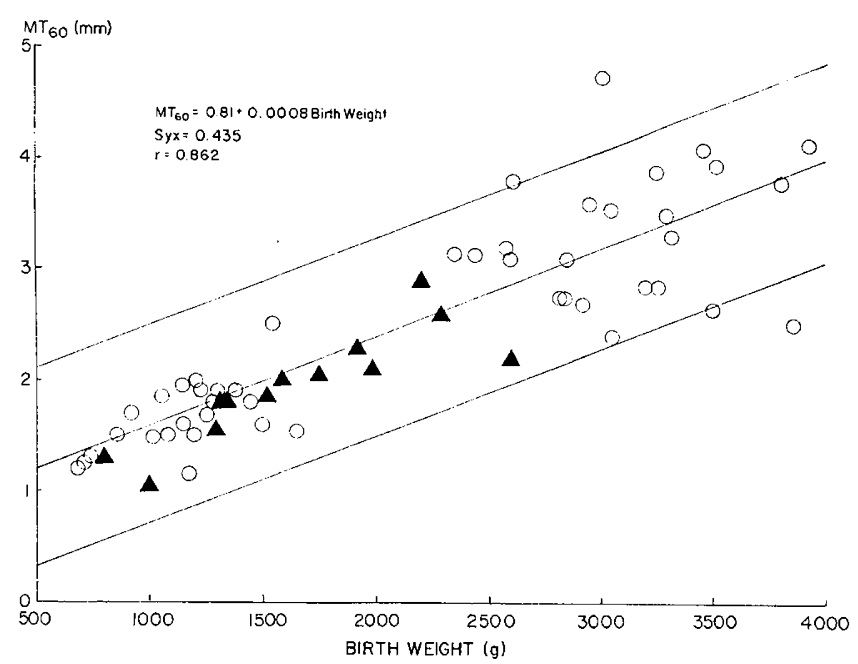

Fig. 2. Scatterplot of midtricipital skinfold thickness recorded $60 \mathrm{~s}$ after caliper application $\left(M T_{00}\right)$ versus birth weight for normally grown $(O)$ and intrauterine growth-retarded $(\mathbf{A})$ infants. The regression $( \pm 2$ Syx $)$ for normally grown infants only has been drawn. Similar results were obtained at the subscapular site as $60 \mathrm{~s}\left\langle\mathrm{SS}_{60}=0.81+0.0009\right.$ birth wt, $\mathrm{Syx}=0.223$, $\mathrm{r}=0.874)$.

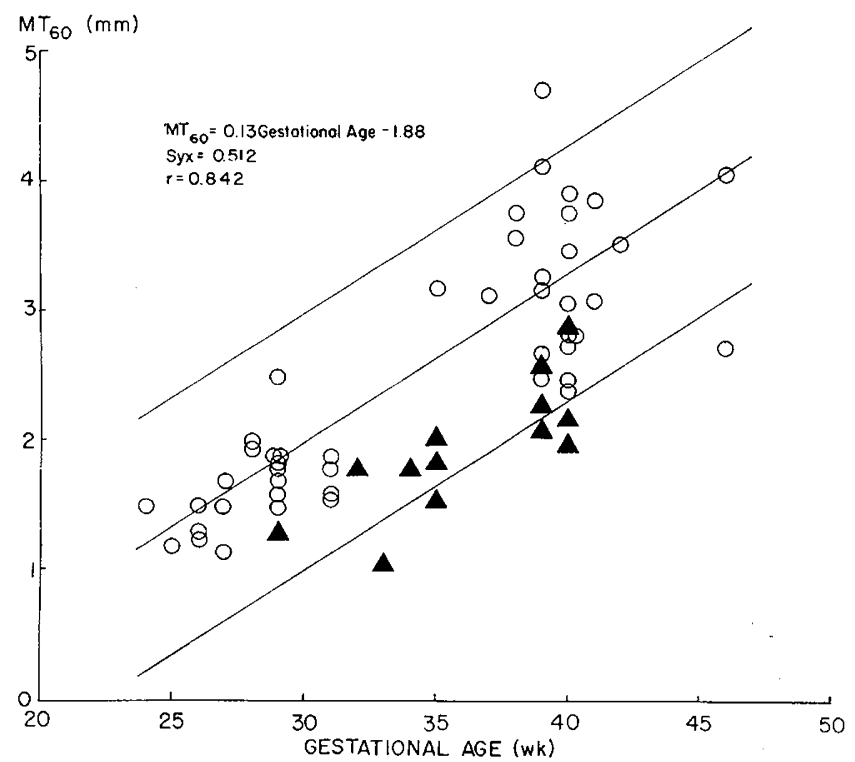

Fig. 3. Scatterplot of 60 -s midtricipital reading ( $\left.M T_{60}\right)$ values versus gestational age for normally grown $(O)$ and intrauterine growth-retarded $(\boldsymbol{\Delta})$ infants. The regression ( \pm 2 Syx) for normally grown infants only has been drawn. Similar results were obtained at the subscapular site at $60 \mathrm{~s} \quad\left(\mathrm{SS}_{\mathrm{6} 0}=0.13\right.$ gestational age -1.81, Syx $=0.604, \mathrm{r}=0.804$ ).

2,500 g and gestational ages between 30 and 38 weeks precluded definitive conclusions. Intrauterine growthretarded infants followed the same trend as their NG weight peers, with all but 1 falling within 1 Syx of the calculated regression line, but deviated markedly from their NG gestational peers. All but 2 IGR infants have $\mathrm{MT}_{60}$ values more than $1 \mathrm{Syx}$ below the regression line and 5 of 13 deviated by more than 2 Syx.

As shown in Figure 4, percentage $\triangle \mathrm{SFT}$ was inversely proportional to gestational age. The correlation coefficients of -0.777 for percentage $\triangle M T$ and -0.773 for percentage $\Delta S S$ were highly significant $(P<0.001)$. The variable was not affected by impaired intrauterine growth. No variation of percentage $\Delta S F T$ with birth weight (Fig. 5) occurred in the mature neonates, but in premature infants percentage $\Delta$ SFT tended to be higher with lower birth weights, with moderate but significant correlation coefficients of -0.479 for percentage $\triangle \mathrm{MT}$ and -0.520 for percentage $\Delta \mathrm{SS}(P<0.01)$. There was a moderate but highly significant correlation between percentage $\Delta S F T$ and maximal postnatal weight loss (percentage $\Delta W)(r=0.579$ for MT and 0.553 for SS, $P<0.001$ ) (Fig. 6). Finally, an inverse correlation was evident between percentage $\triangle \mathrm{SFT}$ and $\mathrm{SFT}_{60}(\mathrm{r}=-0.675$ for MT and -0.724 for SS, $P<$ $0.001)$.

\section{Discussion}

Although calipers have been used extensively to measure skinfolds, they are deceptively easy to use. In fact a

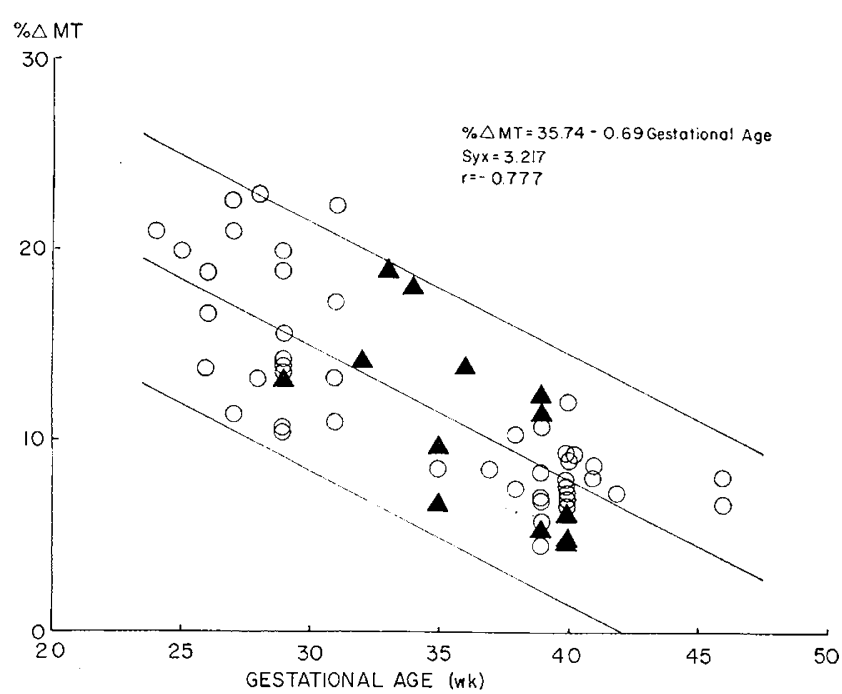

Fig. 4. Scatterplot and regression $( \pm 2$ Syx) of the difference between 15 - and 60 -s skinfold measurements in percentage of the 15 -s reading versus gestational age. $\bigcirc$ : normally grown; A: intrauterine growth-retarded infants. Similar results were obtained at the subscapular site (percentage $\Delta S S=37.83-0.73$ gestational age, Syx $=3.448, \mathrm{x}=-0.773)$. 
single observer can expect an accuracy of only $\pm 5 \%$ and differences of $10 \%$ among several observers are not uncommon [18]. Great care must be exercised in locating the proper measuring point.

Skinfolds contain a double layer of skin and subcutaneous tissues and the latter are commonly equated to subcutaneous fat $[1,6,17,19,41,45-47]$. Several investigators note some decline in the SFT readings after application of a Harpenden caliper in children and adults. Fletcher records cinematographically a 3-9\% decline over a 2-5-s period [22]. Booth et al. mention waiting for all needle movements to cease before taking the reading [5]. Orpin and Scott [41] observe an initial rapid phase of movement of the needle and read the SFT when the movement has stopped, which could not be very long inasmuch as they perform 27 measurements in $10 \mathrm{~min}$. No explanation of the decline is attempted. The observation that the magnitude of this decline in the neonate follows a definite pattern related to the degree of gestational maturity and intrauterine growth suggests that the skinfold contains some compressible or expressible component.

No data on skin thickness in the neonate have been published. Clinical observations of increased skin fragility in the tiny premature infant indicate that variations in thickness do occur, but it is assumed that the rate of increase in skin thickness during fetal life is negligible compared with that of subcutaneous fats.

The phase of exponential decline of SFT measurements under caliper pressure (Fig. 1) could result either from fat undergoing compression or from fat globules or interstitial water being expressed from the skinfold. Compression or expression of fat is unlikely since the relative amount of compression or expression (percentage $\Delta$ SFT) would be directly proportional to the total amount of material $\left(\mathrm{SFT}_{60}\right)$ unless qualitative changes in adipose tissue composition also occur. No data which support this possibility are available at the present time. More probably, percentage $\Delta \mathrm{SFT}$ is a reflection of subcutaneous interstitial water. Cassady [12] and Cassady and Milstead [13] demonstrated that the proportion of body mass occupied by extracellular water or by total body water is an inverse function of gestational maturity and that intrauterine growth retardation results in a relative expansion of both compartments. Hohenhauer and $\mathrm{Oh}$ [30] found an increased proportion of total body water in intrauterine growth-retarded rats. Yet Lugo et al. [36] found no differences in the proportion of water between carcasses of IGR and NG rats. They explain the apparent paradox by selective water retention in visceral organs

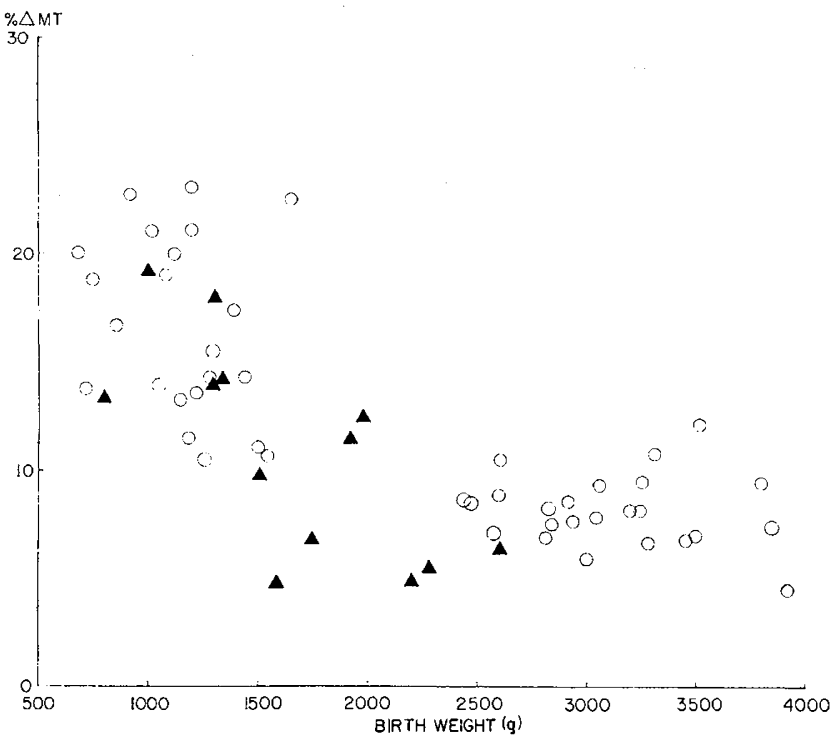

Fig. 5. Scatterplot of difference between 15- and 60-s skinfold measurements in percentage of the 15 -s reading $(\% \Delta M T)$ values versus birth weight. $\bigcirc$ : normally grown; $\boldsymbol{\Delta}$ : intrauterine growth retarded. Similar results were obtained at the subscapular site.

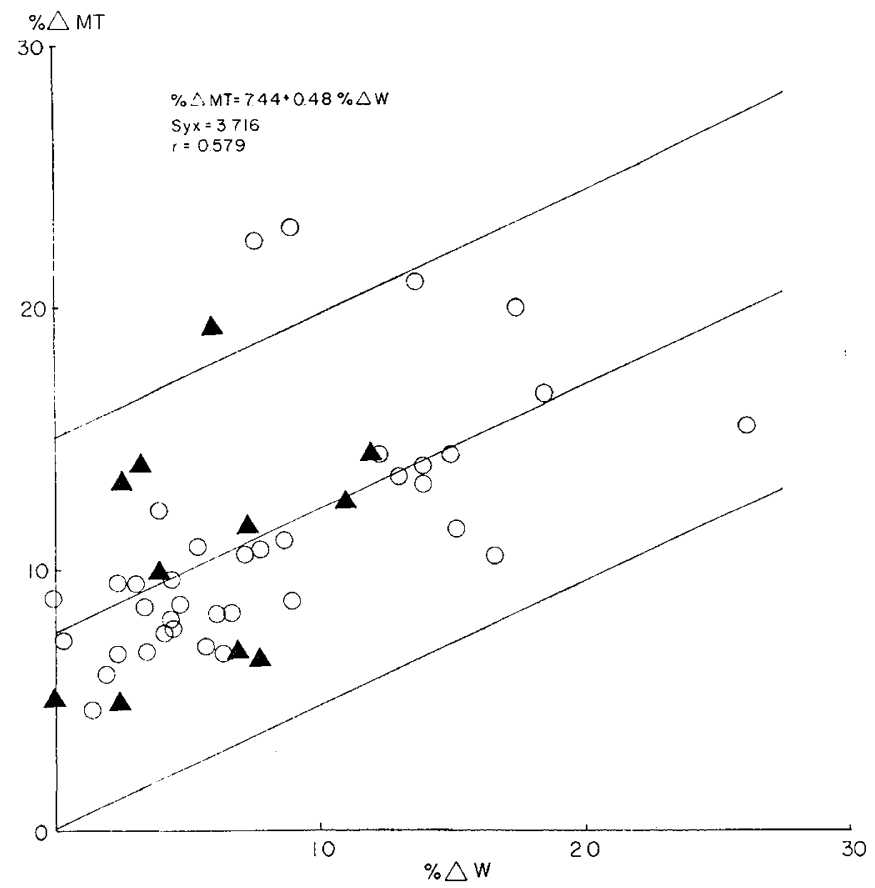

Fig. 6. Scatterplot and regression ( \pm 2 Syx) of difference between 15- and 60-s skinfold measurements in percentage of the 15 -s reading $(\% \Delta M T)$ values versus maximal postnatal weight loss $(\% \Delta W)$. Similar results were obtained at the subscapular (SS) site (percentage $\Delta \mathrm{SS}=8.01+0.47 \% \Delta \mathrm{W}$, Syx $=3.979, \mathrm{r}=$ $0.553)$. 
rather than in carcass tissues. The present study reveals that the proportion of subcutaneous expressible material (percentage $\Delta S F T$ ) is inversely related to duration of gestation and is not affected by impaired intrauterine growth (Fig. 4). These trends are strikingly similar to those of direct extracellular water measurements and are compatible with the contention that the expressible material is indeed interstitial water and that percentage $\triangle \mathrm{SFT}$ constitutes an estimate of subcutaneous interstitial water. It is interesting to note further that percentage $\Delta$ SFT (interstitial water) is apparently related to postnatal weight loss (Fig. 6).

The amount of subcutaneous fat deposition, estimated from the $\mathrm{SFT}_{60}$ measurements, is directly proportional to birth weight (Fig. 2). It also correlates well with gestational age in NG infants (Fig. 3). The effect of impaired intrauterine growth is apparent in the mature group only, whereas the similar effect in the premature group is masked by a difference in maturity between NG and IGR prematures. In fact, all IGR-P infants have $\mathrm{MT}_{60}$ values below the mean expected for their gestational age with 6 of 7 deviating by more than 1 Syx and 2 of 7 deviating by more than 2 Syx. In other words, impaired intrauterine growth as well as immaturity appear to affect fat deposition in the subcutaneous tissues. Usher [48] and Usher and Tanner [49] show the same effect of intrauterine growth retardation on the abdominal skinfold, but Lugo et al. [36] find equal amounts of fats in the carcasses of IGR rats and in those of their NG sibs. Resolving this discrepancy requires further investigation.

Whether these trends may be extended to total body fats is speculative. Hohenhauer and $\mathrm{Oh}$ [30] found decreased total body fat stores in IGR rats. Published data on gravimetrically determined fat contents in 103 fetuses $[4,7-10,14,20,21,31,33,40,50,51]$ indicate that the proportion of fat increases linearly with increasing birth weight (Fig. 7: $\mathrm{r}=0.945, P<0.001$ ). Because subcutaneous fats, estimated by $\mathrm{SFT}_{60}$ measurements, also increase linearly with birth weight, it seems reasonable to postulate a linear relation between subcutaneous and total body fat stores in the newborn. Assuming these relations to be true, skin fold measurements provide a useful tool in perinatal body composition and nutrition studies, and allow determination of the respective proportions of weight gain that can be attributed to fat deposition and to water accumulation. Attempts at correlation of skinfold measurements with chemical analysis of cutaneous and subcutaneous tissues collected at necropsy are the objects of present investigations in this laboratory.

\section{Summary}

Midtricipital and subscapular skinfolds are measured within $24 \mathrm{hr}$ of birth in 59 infants which belong to

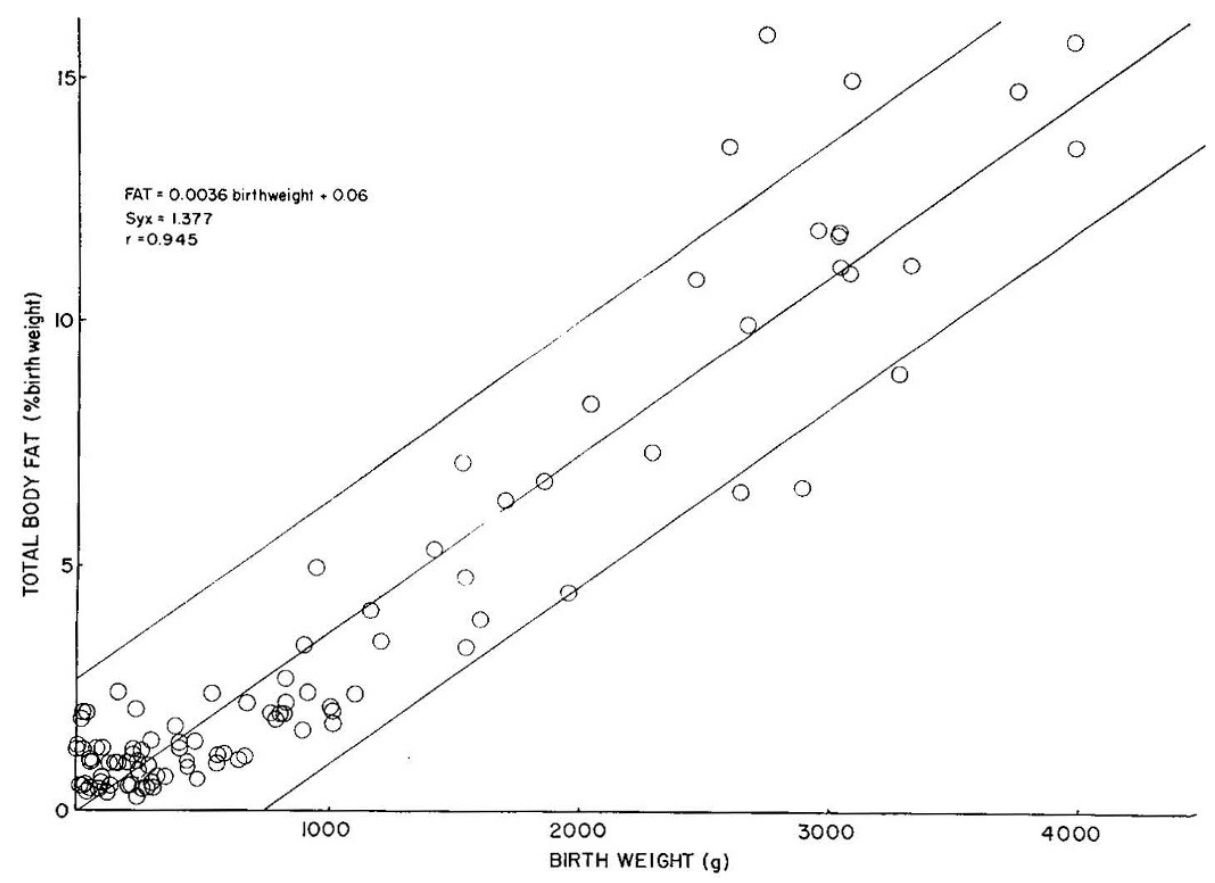

Fig. 7. Scatterplot and regression $( \pm 2 \mathrm{Syx})$ of total body fat versus birth weight according to the literature. 
four groups: normally grown mature and premature and intrauterine growth-retarded mature and premature. Measurements are recorded 15 and $60 \mathrm{~s}$ after application of a Harpenden caliper.

The amount of subcutaneous fat, estimated from the 60-s reading, is affected by duration of gestation and by impaired intrauterine growth. Inasmuch as a linear relation exists between both amount of subcutaneous fat and total body fat stores, caliper measurements may also provide an estimate of the latter.

The difference between the 15- and 60-s readings, expressed in percentage of the 15 -s reading, is directly related to postnatal weight loss and gestational immaturity in all infants and indirectly related to birth weight in the premature group only. The similarity of these trends with those of direct extracellular water measurements indicates that they may constitute an estimate of subcutaneous interstital water.

Caliper skinfold measurements may therefore provide a useful, simple, noninvasive tool for perinatal body composition and nutrition studies.

\section{References and Notes}

1. Allen, T. H., Peng, M. T., Chen, K. P., Huang, T. F., Chang, C., and Fang, H. S.: Prediction of total adiposity from skinfolds and the curvilinear relationship between external and internal adiposity. Metabolism, 5: 346 (1956).

2. Bielecka-Winnicka, A.: An attempt to determine hydration changes in subcutaneous and muscular tissues of a newborn by conductometric method. Ann. Paediat., 204: 377 (1965).

3. Biflecka-Winnicka, A.: Hydration in tissues of newborns with too-low weight at birth. Ann. Paediat., 207: 125 (1966).

4. Bischorf, E.: Einige Gewichts und Trocken-Bestimmungen der Organe des menochlichen Korpers. Z. Ration. Med., 20: 75 (1863).

5. Booth, R. A. D., Goddard, B. A., ANd PAton, A.: Measurements of fat thickness in man: A comparison of ultrasound, Harpenden calipers and clectrical conductivity. Brit. J. Nutr., 20: 719 (1966).

6. BrozeK, J., AND Keys, A.: The evaluation of leanness-fatness in man: Norms and interrelationships. Brit. J. Nutr., 5: 194 (1951).

7. Brubacher, H.: Ueber den Gehalt an anorganischen Stoffen, besonders an Kalk, in den Knochen und Organen normaler und rhachitischer Kinder. Z. Biol., 27: 517 (1890).

8. Camerer, W.: Die chemische Zusammensetzung des Neugenorenen. Z. Biol., 40: 529 (1900).

9. Camerer, W.: Die chemische Zusammensetzung des Neugeborenen. Z. Biol., 39: 173 (1900).

10. Camerer, W.: Die chemische Zusammensetzung des Neugeborenen. Menschen. Z. Biol., 43: 1 (1902).

11. Cassady, G.: Plasma volume studies in low birth weight infants. Pediatrics, 38: 1020 (1966).

12. Cassady, G.: Bromide space studies in infants of low birth weight. Pediat. Res., 4: 20 (1970).
13. Cassady, G., and Milstead, R. R.: Antipyrine space studies and cell water estimates in infants of low birth weight. Pediat. Res., 5: 673 (1971).

14. DJu, M. Y., MASON, K. E., A.ND Frler, L. J.: Vitamin E (tocopheral) in human fetuses and placentae. Études Neonat., 1: 49 (1952).

15. Dubowitz, L. M. S., Dubowrtz, V., ANd Goldberg, C.: Clinical assessment of gestational age in the newborn infant. J. Pediat., 77: 1 (1970).

16. Durnin, J. V. G. A., And Rafaman, M. M.: The assessment of the amount of fat in the human body from measurements of skinfold thickness. Brit. J. Nutr., 21: 681 (1967).

17. Edwards, D. A. W.: Observations on distribution of subcutaneous fat. Clin. Sci., 9: 259 (1950).

18. Edwards, K. D. G., And Whyte, H. M.: The simple measurement of obesity. Clin. Sci., 22: 347 (1962).

19. Edwards, D. A. W., Hammond, W. H., Healy, M. J. R., TANneR, J. M., AND Whitehouse, R. H.: Design and accuracy of calipers for measuring subcutaneous tissue thickness. Brit. J. Nutr., 9: 133 (1955).

20. FEE, B. A., AND WEIL, W. B.: Body composition of infants of diabetic mothers by direct analyses. Ann. N. Y. Acad. Sci., 10: 869 (1963).

21. Fehiding, H.: Beiträge zur Physiologie des placentaren Stoffverkerrs. Arch. Gynakol., 2: 523 (1877).

22. Fletcher, R. F.: The measurement of total body fat with skin-fold calipers. Clin. Sci., 22: 333 (1962).

23. Freeman, M. G., Graves, W. L., and Thompson, R. L.: Indigent Negro and Caucasian birth-weight-gestational age tables. Pediatrics, 46: 9 (1970).

24. Frisancho, A. R., AND GARN, S. M.: Skinfold thickness and muscle size: Implications for developmental status and nutritional evaluation of children from Honduras. Amer. J. Clin. Nutr., 24: 541 (1971).

25. Frisancho, A. R., and Garn, S. M.: The implications of skinfolds and muscle size to developmental and nutritional status of Central American children. 3. Guatemala. Trop. Geogr. Med., 23: 167 (1971).

26. Frisancho, A. R., Garn, S. M., ANd Mooreery, L. D.: Relationship of skinfolds and muscle size to growth of children. I. Costa Rica. Amer. J. Phys. Anthropol., 35: 85 (1971).

27. GARN, S. M.: Anthropometry in clinical appraisal of nutritional status. Amer. J. Clin. Nutr., 11: 418 (1962).

28. Gieiss, J., and Hermanns, M.: Ektodermale Kriterien zur klinischen Reifesbestimmung Neugeborenen. Arch. Kinderheilk., 179: 266 (1969).

29. Gurney, J. M., Fox, H., AND Nerll, J.: A rapid survey to assess the nutrition of Jamaican infants and young children in 1970. Trans. Roy. Soc. Trop. Med. Hyg., 66: 653 (1972).

30. Hohenfauer, L., AND OH, W.: Body composition in experimental intra-uterine growth retardation in the rat. J. Nutr., 99: $23(1969)$.

31. Iob, V., And Swanson, W. W.: Mineral growth of the human fetus. Amer. J. Dis. Child., 47: 302 (1934).

32. Keys, A., and Brozek, J.: Body fat in adult man. Physiol. Rev., 33: 245 (1953).

33. Langstein, L., and Edelstern, F.: Die chemische Susammensetzung frühgeborener Säuglinge und ihr Wachstumsansatz. Z. Kinderheilk., 15: 49 (1916).

34. Lesser, G. T., Perl, W., ANd Steele, J. M.: Determination of total body fat by absorption of an inert gas; measurements 
and results in normal human subjects. Clin. Invest., 39: 1791 (1960).

35. Lesser, G. T., AND ZAK, G.: Measurements of total body fat in man by the simultaneous absorption of two inert gases. Ann. N. Y. Acad. Sci., 110: 40 (1963).

36. Lugo, G., O'NeIL, L., AND CASSAdy, G.: Carcass water, fat, and chloride in the fetal growth-retarded rat. Amer. J. Obstet. Gynecol., 110: 358 (1971).

37. McCance, R. A., And Widdowson, E. M.: Composition of the body. Brit. Med. Bull., 7: 297 (1951).

38. Malcolm, L. A.: Growth, malnutrition and mortality of the infant and toddler in the Asai Valley of the New Guinea Highlands. Amer. J. Clin. Nutr., 23: 1090 (1970).

39. Marshall, M. W., Smith, B. P., Munson, A. W., ANd LehMANN, R. D.: Prediction of carcass fat from body measurements made on live rats differing in age, sex and strain. Brit. J. Nutr., 23: 353 (1969).

40. Michel, C.: Sur la composition organique et minérale du foetus et du nouveau-né. Obstétrique, 5: 252 (1900).

41. ORPin, M. J., ANd Scotr, P. J.: Estimation of total body fat using skinfold caliper measurements. New Zealand Med. J., 63: 501 (1964).

42. Parizkova, J.: Total body fat and skinfold thickness in children. Metabolism, 10: 794 (1961).

43. Seltzer, C. C., Goldman, R. F., and Mayer, J.: The triceps skinfold as a predictive measure of body density and body fat in obese adolescent girls. Pediatrics, 36: 212 (1965).

44. Sumners, J., Brans, Y., Dweck, H., Lockard, W., and CAssady, G.: A non-invasive approach to body composition in the newborn: Dynamic skinfold measurements (Abstract). Pediat. Res., 7: 179 (1973).
45. Tanner, J. M.: The measurement of body fat in man. Proc. Nutr. Soc., 18: 148 (1959).

46. TANner, J. M., AND WhrTehouse, R. H.: The Harpenden skinfold caliper. Amer. J. Phys. Anthropol., 13: 743 (1955).

47. Tanner, J. M., and Whitefouse, R. H.: Standards for sub. cutaneous fat in British children. Brit. Med. J., 1: 446 (1962).

48. Usher, R. H.: Clinical and therapeutic aspects of fetal malnutrition. Pediat. Clin. N. Amer., 17: 169 (1970).

49. Usher, R., ANd MCLean, F.: Intrauterine growth of live-born Caucasian infants at sea level: Standards obtained from measurements in 7 dimensions of infants born between 25 and 44 weeks of gestation. J. Pediat., 74: 901 (1969).

50. Widdowson, E. M., and Dickinson, J. W. T.: Chemical composition of the body. In: C. L. Comar and F. Bronner: Mineral Metabolism: An Advanced Treatise, Vol. II, p. 2 (Academic Press, N. Y., 1964).

51. Widnowson, E. M., ANd Spray, C. M.: Chemical development in utero. Arch. Dis. Childhood, 26: 205 (1951).

52. The authors gratefully acknowledge the assistance of Penny Bailey and Olivia Knopf in the preparation of this manuscript.

53. This research was supported by Maternal and Infant Care Project no. 544, Children's Bureau, Social and Rehabilitation Service, Department of Health, Education and Welfare and Ross Laboratories, Columbus, Ohio.

54. Requests for reprints should be addressed to: Y. W. BRANs, M.D., Perinatal Research Laboratory, University of Alabama Medical Center, University Station, Birmingham, Ala., 35294 (USA).

55. Accepted for publication November 13, 1973. 